\title{
Obtaining a PhD: Personal experience of a nurse
}

\author{
Drita Puharić ${ }^{*}$ \\ PhD student at the School of Medicine, University \\ of Split, Split, Croatia \\ ${ }^{*}$ Corresponding author: \\ drita.puharic@hotmail.com \\ Tel.: + 38521557820 \\ Fax.: + 38521557820
}

Received/Accepted: 10 August 2015

Key words: Nursing - Education - Encouragement and cooperation - Mentoring - Research.

I read with great interest the article by Sambunjak (1) on mentoring, and the reactions it evoked. It prompted me to offer my own experience as a nurse attending a postgraduate program, with hopes that it may serve the worldwide community of nurses through encouragement, advice and vivid description.

First, I want to tell my colleagues not to be afraid of postgraduate studies. Nursing needs to rise to higher levels than it is today, as it plays an important role in ensuring safe and effective patient care. Drawing upon evidence based medicine, nursing needs to carry out competitive and high quality research. And in order to do so, nurses need to engage and adopt scientific and critical thinking, and partake in cooperation and exchange of experiences. In Croatia, after finishing nursing school, which is a secondary school that students usually enter at age 13-14, nursing education can be continued on three levels: pregraduate (baccaleurate), graduate (master's level), and postgraduate (doctoral) (2).

I did my master's thesis on the attitudes towards sexual health and contraception and my mentor was prof. A. M. Several months later, her husband prof. M. M. asked me: "What's next?" and advised I continue my education at the postgraduate program, where, if I was interested, I would be able to deepen my knowledge and acquire new skills by engaging in research, and learning truly what it means to develop a topic, do literature search, apply constructive criticism, and collect and analyse data. I was unsure at the time, and when he asked me: "Where do you see yourself in the future - what would you like your lifelong work to be? I replied: "Working with mothers and children." Immediately he said: "Great, let's go to the Department of Family Medicine, where a very capable researcher has finished a $\mathrm{PhD}$ on the subject." I didn't really even have time to think, or acknowledge my fear, when there she was, at her desk, doctor IZG. We were introduced, and professor asked her out of the blue if she was willing to be my mentor. She, as was I, was caught by surprise, and before she could give an answer, the professor's wife comes in, he tells her the plan, and she says: "Dear I., Drita was my student, I mentored her master thesis, and I can say with certanty you will not regret if you accept mentoring". And so I was given my first task, by my new mentor(s), to write a research 
plan of the format that medical schools students write at the School of Medicine in Split for their theses (3). Walking to the car, I felt tears running down my face. I was terrified, in my head swarmed all kinds of thoughts and none of them were reassuring.

But, after a few meetings, a title emerged: "The effect of educational interventions on the practice of breastfeeding in primipara: a prospective, randomized controlled trial." In drafting the protocol, I had help from a young colleague M. Mal and I learned to follow the CONSORT guidelines (3), to describe in detail the intervention, and check for the possibility of systematic errors, or biases that could effects the results (4). Then, it was time to carry out the literature search on the subject. With the help of A. U., head of the Central Medical Library at the School of Medicine, I had in front of me 496 abstracts that had to be read (at the time I was shocked, but later I even had to go through some 2000). My mentor advised me to summarize all these articles in a table, and list several characteristics of each, including the intervention, its effects, and the limitations of the study. And so I read, and learned.

In December 2011 came the call for admission to Translational Research in Biomedicine programme. By then I had already developed my research topic and almost the entire study protocol. But I was scared when I was scheduled for the interview for admission. What was I to say? I stopped by at professor's M.M. office for encouragement, but what I got was strictness and an objection to the fact that my proposal had two typographical errors: "The future scientist should not have mistakes in the text." I felt tears gathering and asked: "Will the interview be very difficult?" He waved his hand and said: "You do not have to be afraid, just tell them why you want it and what is your plan". Then he noticed my tears, and consoled me in his typical manner: "Why do you wear makeup if you are going to cry?" The interview, nee- dles to say, went really smoothly. In February I was accepted. And then the studying, socializing, and tears began anew. Each year, we had tests, and two reports of our progress which we needed to present to the heads of the program and our colleagues.

Still there was a lot I did not know; my mentor and I were not sure whether our study should be single or double blind, how to develop a leaflet about the benefits of breastfeeding and how to approach the mothers about the study. And so we asked for help, from three different individuals, all knowledgeable about one particular thing. A month went by, and professor P. H. came one day from England to give a lecture on qualitative research. She had conducted a series of studies on breastfeeding and advised us to record all the conversations I would have with the mothers, and also told us to register the study. As our plan was now finished, we obtained the positive opinion from the Ethics Committee of the Medical School and in July 2014, we entered our study in the registry ClinicalTrials.gov. Just this month, we finished writing the full protocol in English, and have sent it out for publication.

After registration of the study, I arranged with gynaecologists in nine clinics to enable me to recruit pregnant women. At first, it worked well, but as time went on some gynaecologists, pressured with their work, irregularly sent data I needed. So I started to visit them regularly and call them up, and I am still doing it. It is hard, and takes a lot of time, but it gets the work done. Once I obtain the demographic data, I randomize women according to a predefined protocol; open a file for each one, with their name, intervention group, gynaecologist, address, phone number, and date of interventions and calls that I need to make. And even though the study is big and complicated, and I am doing repeated measurements three times, listening to mothers while they talk about their children and their desire to provide the best for them 
is inspiring. I have included 300 women in the study, did more than 300 telephone interventions, and received some 360 text messages from mothers asking me advice.

In my second year professor M. M. asked: "Is it hard?". But I needed a second to reply, to think, cause I did not even have the time to think about that. "Yes, it is difficult" I said, "but it can be done." Through the hardship, you meet so many kind, helpful, and wonderful people, you get to work with respected professors and colleagues, and see the same fright and tears in new generations that I used to have. And that is perhaps the biggest treasure of it all, a new world of experiences opens. And that is my second advice, if we want nursing to evolve, we need to evolve with it.
Conflict of interest: The author of the comment (D.P.) was a mentee of the first author of the article in the ref. 3 .

\section{References}

1. Sambunjak D. Understanding wider environmental influences on mentoring: Towards an ecological model of mentoring in academic medicine. Acta Med Acad. 2015;44(1):47-57.

2. Marušić M, Mimica M, Mihanović F, Janković S. Doctoral degree in health professions: Professional needs and legal requirement. Acta Med Acad. 2013;42(1):61-70.

3. Marušić A, Malički M, Sambunjak D, Jerončić, Marušić M. Teaching science throughout the sixyear medical curriculum: Two-year experience from the University of Split School of Medicine, Split, Croatia. Acta Med Acad. 2014;43(1):50-62.

4. Schulz KT, Altman DG, Moher D; CONSORT Grup. CONSORT 2010 statement: updated guidelines for reporting parallel group randomized trials. Ann Intern Med. 2010;152(11):762-32. 